Brit. J. Psychiat. (1976), 128, 308-12

\title{
Correspondence
}

Letters for publication in the Correspondences columens should be addressed to:

The Editor, British Journal of Psychiatry, 17 Belgrave Square, London, SW IX 8PG

\section{FACT AND FICTION IN THE GARE OF THE MENTALLY HANDICAPPED}

Drar SIR,

Dr Shapiro's historical account is both elegant and illuminating. But if history teaches us anything, it is not that the solutions of the past were best, but rather that we need not be bound by the solutions we have inherited. If 'community care' in the past was inadequate, this is not to say that it will always be so, given the proper planning and development of services. If the institutions, in their day, offered a service guided by enlightened concepts, this is not to say that institutional care is now appropriate. It is perhaps salutary to note that these same concepts were guiding a service which has thrown up what Dr Shapiro euphemistically calls the 'painful occurrences' at Ely, Farleigh, etc. The gap between the 'concepts' of great consultants and the realities of service provision-care on the wards-has grown too wide.

In the latter part of his paper there is an argument for medical specialization which few could deny. For too long there has been a failure to recognize the special medical and psychiatric needs of many mentally handicapped people. But Dr Shapiro makes an illogical step from the issue of specialization to that of the control of services. He over-stresses these special physical and psychiatric needs, and understates the importance of purely social care. He argues that the medical specialist is uniquely able to perform the role of co-ordinator of the team of specialists, though his unique qualifications for co-ordinating the work of teachers, social workers, psychologists and others are not specified. By a trick of definition, social psychiatry becomes :. . . the adjustment of the total individual to his emotional and social environment'. I imagine the definition would just as easily fit the specialisms of nurses, teachers, social workers, psychologists and others, all of whose work is devalued by Dr Shapiro's argument.

His concern with control becomes at times almost obsessive, with mention of assuming $4 .$. . total control of the patient', and the '. . . total management of a patient in relation to his environment'. But his case for the medical specialist assuming this control, this paramount position, is neither clearly nor convincingly presented.

Professionalism is a sentiment which can inspire the highest standards of service and care. But it has another face, which can become a narrow, jealous concern with the privileges, status and rewards of an occupational group. It would be a pity if consultants, and nurses too, allowed this kind of sentiment to cloud their judgement. Services should be planned around the needs of clients, not the career prospects of professionals. The needs of the mentally handicapped can only be met by services which are truly interdisciplinary in character. Medical specialists are a vital part of any caring team-but contributions from nurses, social workers, teachers, psychologists and parents are just as vital. Historically, medical men have not been accustomed to assuming such a role, but it is to be hoped that they will accept the challenge rather than cry for a return to the old ways.

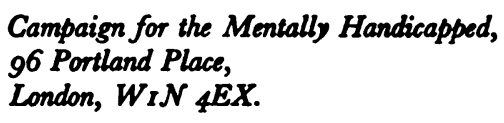

\section{Dear Sir,}

It is very nice to be able to welcome Dr Forrest (Journal, August 1975, 127, p 190) to the increasing number of professionals who believe that the hospital service for the mentally handicapped has become a casualty of the reorganization of the NHS, and that some unification of the service, whatever its disadvantage in 'isolating' this group from other handicapping conditions, should be considered at this stage. This is a realistic view and it has my support.

However, this does not seem to me necessarily to support the views of Dr Shapiro (Joumal, September 1974, 125, P 286) or to condemn those of Dr Kushlick and his colleagues (Joumal, May 1975, 126, p 487). Dr Shapiro appears to promote a medically-orientated comprehensive service in which large hospitals continue as the basis for a psychiatrically-orientated service. This seems also to have been the style, if not 
the method of funding, of the old service in Northern Ireland, which Dr Forrest favours. There are, however, other ways of developing a unified service, not based on the medical model as we have known it in the past but respecting the multi-disciplinary approach, which is now generally accepted as being the most appropriate one.

On the other hand, the approach of Dr Kushlick and his colleagues is based upon the principles embodied in Better Services for the Mentally Handicapped (which are also contained, with detailed modification, in the Scottish equivalent, Seroices for the Mentally Handicapped). There is, it seems to me, a valuable thread of agreement here, even between somewhat polarized extremes, and it is most important in the present turbulent state that this possibility for the development of an articulate and unified voice for this vulnerable sector should be pursued.

It appears to some of us that one major cause of the emotive dissonance that has characterized this field in recent years is the lack of understanding between various professionals. It has been the experience of the Association of Professionals for the Mentally Handicapped that if such professions undergo even a short educational experience together they gain much more insight into the roles of their colleagues in other disciplines.

What is urgently needed in the United Kingdom is an academic centre, or centres, for the training of professionals in mental handicap. There appear to be many areas of overlap in parts of existing courses which are at present taken in isolation by nurses, social workers, educationalists, para-medicals, psychologists and the students in the various medical sub-specialties. There are also areas in which no one seems to receive adequate training. If the mental handicap aspects of these courses could be received in the same setting with students from other disciplines: ( 1 ) a better perspective and a more balanced approach would be promoted among professionals; (2) the content of the courses could be considerably refined, especially with regard to their relevance to the ultimate professional tasks; and (3) a centre (or centres) of excellence would be created which would attract the comparatively few skilled people who are around in this field to work together in a balanced multi-disciplinary setting from which some original ideas and research could hardly fail to materialize. It is, of course, essential that such an 'Institute' should be located in a situation, both functionally and geographically, that does not give it, directly or by implication, a unidisciplinary slant. It might be possible, for example, to attach it to a University but not necessarily through the Departmental structure, and it should not be difficult-with funding - to direct it at Professorial level.

It has been my sad experience in recent years to see an increasing polarization of the views upon the services for the mentally handicapped. The result of this has been to prevent the effective development of new ideas on any worthwhile scale. The causes are complex-political, economic, psychosocial, technological developments in medicine, etc. The faith of Better Services (40)(xiii) in the reorganization of the NHS does not seem to those of us actually involved in the service to have been justified. I suggest that our task now is to co-operate within ourselves and with our colleagues in all the related disciplines in the setting up of a truly 'Better Service' that compounds experience, insight, and above all, better professional skills, knowledge and attitudes.

\section{T. L. Punneton}

Department of Community Medicine,

Usher Institute,

Warrender Park Road,

Edinburgh, EHg IDW.

Drar Sir,

We are surprised that Dr Halliday et al (Foumal, October $1975,127,4^{16}$ ) did not refer to pulse ECT when discussing the prevention of memory disturbance after ECT. We agree that there are three considerations in achieving this-the use of unilateral non-dominant electrode placement, correct assessment of laterality and employment of the minimum dose required to produce grand mal. With regard to the third, we believe that they have overlooked an efficient and widely available method, namely the use of bidirectional pulses, $750 \mathrm{~V}$ peak-to-peak with a repetition rate of $21 \cdot 5$ per second. The wave form thus differs radically from that of sinusoidal ECT. Pulse ECT has been adequately described (Cronholme and Ottosson, 1963: Carney and Sheffield, 1974) andit has been shown in controlled comparative studies to be as beneficial as sinusoidal ECT by Valentine, Keddie and Dunne (1968) who also showed that it reduced to a significantly greater extent than sinusoidal ECT, post-electroplexy malaise and memory disturbance.

M. W. P. Garney

Northwick Park Hospital, Watford Road, Harrow, Middlesex HAI $3 \mathrm{UJ}$.

University Hospital of

B. F. Shatrerd

South Manchester. 